\title{
A Four-Step Cascade Drug-Release Management Strategy for Transcatheter Arterial Chemoembolization (TACE) Therapeutic Applications
}

\author{
Ying-Jiun Hsieh ${ }^{1,+}{ }^{\dagger}$ Hung-Wei Cheng ${ }^{2,+}$, Hung-Yu Chen ${ }^{3}$ and Ming-Wei Lee ${ }^{1,3,4, *}$ \\ 1 Graduate Institute of Technology Management, National Chung Hsing University, Taichung City 402, Taiwan; \\ arborfish@dragon.nchu.edu.tw \\ 2 Department of Materials Science and Engineering, National Chiao Tung University, Hsinchu 30010, Taiwan; \\ mlb14756@gmail.com \\ 3 Department of Clinical Laboratory, Chung Shan Medical University Hospital, Taichung 40201, Taiwan; \\ c135791010@gmail.com \\ 4 Department of Speech and Language Pathology and Audiology, Chung Shan Medical University, \\ Taichung 40201, Taiwan \\ * Correspondence: d880430@csmu.edu.tw; Tel.: +886-4-24730022 \\ + These authors contributed equally to this work.
}

Citation: Hsieh, Y.-J.; Cheng, H.-W.; Chen, H.-Y.; Lee, M.-W. A Four-Step Cascade Drug-Release Management Strategy for Transcatheter Arterial Chemoembolization (TACE) Therapeutic Applications. Polymers 2021, 13, 3701. https://doi.org/ 10.3390/polym 13213701

Academic Editor: Yury A. Skorik

Received: 20 October 2021

Accepted: 24 October 2021

Published: 27 October 2021

Publisher's Note: MDPI stays neutral with regard to jurisdictional claims in published maps and institutional affiliations.

Copyright: () 2021 by the authors. Licensee MDPI, Basel, Switzerland. This article is an open access article distributed under the terms and conditions of the Creative Commons Attribution (CC BY) license (https:// creativecommons.org/licenses/by/ $4.0 /)$.

\begin{abstract}
The purpose of this study was to develop a four-step cascade drug-release system for transcatheter arterial chemoembolization (TACE) therapeutic applications according to disease-driven and patient-focused design theories. The four steps underlying these strategies involve the blockage of nutrient supply, nanoparticles, codelivery and the cell cytotoxic effect. Calibrated spherical gellan gum (GG) and nanoparticle-containing gellan gum microspheres were prepared using a water-inoil emulsification method. Self-assembled nanoparticles featuring amine-functionalized graphene oxide (AFGO) as the doxorubicin (Dox) carrier were prepared. The results confirm that, as a drug carrier, AFGO-Dox nanoparticles can facilitate the transport of doxorubicin into HepG2 liver cancer cells. Subsequently, AFGO-Dox was introduced into gellan gum (GG) microspheres, thus forming GG/AFGO-Dox microspheres with a mean size of 200-700 $\mu \mathrm{m}$. After a drug release experiment lasting 28 days, the amount of doxorubicin released from 674 and $226 \mu \mathrm{m}$ GG/AFGO-Dox microspheres was 2.31 and $1.18 \mu \mathrm{g} / \mathrm{mg}$, respectively. GG/AFGO-Dox microspheres were applied in a rabbit ear embolization model, where ischemic necrosis was visible on the ear after 12 days. Our aim for the future is to provide better embolization agents for transcatheter arterial chemoembolization (TACE) using this device.
\end{abstract}

Keywords: cascade antitumor drug delivery; gellan gum polysaccharide; graphene nanoparticles; transcatheter arterial chemoembolization

\section{Introduction}

The development of drug delivery systems for disease management at the laboratory stage is often referred to as the initial laboratory phase. The idea behind this is to develop a rational model for drug delivery systems that can be used by stakeholders as a tool to support technology innovation. Barry, S.-T. et al. (2017) [1,2], described the concept of using disease-driven and patient-focused design theories in anticancer strategy development from an industry perspective. In our study, we applied these design theories to develop a drug-release management strategy for hepatocellular carcinoma (HCC) therapy. Disease-driven design is rooted in understanding the implications of biology for cell medicine behavior in order to select a carrier that is able to exploit pathophysiology. The approaches outlined in this article focus on the development of drug delivery strategies for hepatocellular carcinoma therapy and were designed to overcome the limitations of tumor biology by increasing penetration and delivering more drug away from the vasculature, 
in addition to prolonging retention of high concentrations of drug in the tumor, thereby increasing drug availability. In patient-focused design theory, understanding the off-target effects of cancer drugs is as important as evaluating their efficacy. An off-target effect is the biological activity of a drug acting on targets other the intended biological target. It most commonly contributes to side effects [3]. Thus, reducing the side effects of drugs and enhancing safety represent the core of this design. Drugs are delivered to a specific tissue through a delivery system, and drug accumulation is promoted to improve the therapeutic effect as a function of the relative clearance rate of the drug by the tumor and normal tissue [4]. By improving the tolerance of the patient to the drug and reducing its toxicity, the patient can eventually receive a higher lifetime dose. Drug carrier development strategies are based on both theories, i.e., disease-driven design and patient-focused design. A development strategy that is based on the disease-driven design theory usually involves changing the material, structure (such as aperture or size), and surface characteristics of the drug delivery carrier. In order to establish the safety, tolerability and durability of a drug for patients, a development strategy that is based on patient-focused design theory will involve multifunctional carriers and combination therapies as the core of the development. A drug is composed of two parts: the main body (with a pharmaco-logical composition) and the delivery carrier. The drug delivery carrier is an auxiliary component; however, it represents the key target of strategies that are based on the theory of patient-focused design. This allows any systemic adverse reactions that occur during the process of drug administration to be relieved and enables patients to receive higher lifetime doses to cope with malignant (cancer) and chronic diseases.

Accordingly, this study was conducted to design a four-step cascade drug-release management strategy for the treatment of liver cancer patients. The four steps were interrelated, and each had its own important strategy to address the goal of cancer treatment. Each step corresponds to a cancer treatment strategy [5]. The first step was based on nutritional diet strategies, whereby vascular embolization particles were de-signed to block nutrient supply and thereby achieve the purpose of killing cancer cells. According to the concept of patient-focused design, vascular embolism is a local treatment that has fewer side effects than chemotherapy. The second and third steps adopted both a nanoparticle strategy and codelivery strategy, combining graphene nanoparticles with the chemotherapy drug doxorubicin (Dox) [6]. Nanoparticles were used as the drug carrier, as they can prolong the retention time of the drug in the blood as well as reduce opsonin absorption and reticuloendothelial system (RES) recognition [7]. The codelivery strategy allows the cancer cells to increase their uptake of drug in addition to increasing drug penetration into cells [8]. The fourth step involves a cytotoxic strategy, whereby graphene and Dox are transported to the cell and are subsequently separated in response to a $\mathrm{pH}$-sensitive stimulus. Because the main function of Dox is to kill cancer cells, its concentration is a key factor in cancer treatment. The ideal drug carrier enables high bodily availability with a low dose of drug, thereby allowing the patient to receive a higher lifetime dose to fight the disease.

Embolization blocks the blood supply to a tumor, leading to tumor cell death. To enhance their therapeutic effect, chemotherapy drugs are loaded with an embolic agent, a treatment referred to as chemoembolization [9]. Transcatheter arterial chemoembolization (TACE), which is the recommended treatment for mid-stage hepatocellular carcinoma (HCC), allows the drug to be delivered to a localized tumor site and selectively blocks the blood supply to the tumor [10]. TACE has less of an effect on normal cells, since approximately $75 \%$ of the liver's blood supply comes from the hepatic portal vein. Compared to traditional chemotherapy, TACE can control drug release to reduce systemic toxicity and extend its duration at the tumor site, thereby inducing tumor necrosis without an adverse reaction $[11,12]$. Moreover, TACE can induce tumor-associated antigens (TAAs) to activate immune components, such as Th17, CD4 and CD8 T cells [13]. However, some side effects may occur, including pulmonary thromboembolisms, liver abscesses, and bile duct lesions [14]. Embolization reagents are typically designed to achieve good TACE efficacy. There are some requirements for ideal TACE reagents, as follows: (1) quick blockage of 
the blood flow following intra-arterial injection; (2) anticancer drug release for localized treatment; (3) suitable degradation time to prevent thrombi. Current TACE agents (such as microspheres, beads and hydrogels) have been developed using polymers [15].

Conventional TACE (CTACE) and TACE with drug-eluting beads (DEB-TACE) are two types of TACE agents that are currently available [16]. cTACE, which involves a mixture of anticancer drugs and lipiodol and embolization reagents (e.g., gelatin microspheres), is commonly used for HCC treatment, although it can induce serious systemic toxicity and hepatic artery injury [17]. On the other hand, DEB-TACE (e.g., DC bead ${ }^{\circledR}$ ) is a drug delivery system (DDS) for microsphere embolic agents that can successfully increase local drug concentration, leading to tumor necrosis and slow anti-cancer drug release. This reduces the side effects that are caused by CTACE, because chemotherapeutic drugs (e.g., doxorubicin (Dox) and epirubicin) can be loaded into DC beads with sulfonate groups to control release as a function of ionic changes [18]. In addition, the concentration of Dox can be effectively increased, thereby enhancing the therapeutic effect, as shown in a liver tumor rabbit model. One study reported that smaller microspheres $(<100 \mu \mathrm{m})$ can provide more effective embolization than larger microspheres because they can enter the thin branches of blood vessels near a tumor site. However, DC beads ${ }^{\circledR}$ cause irreversible embolism at the targeted site, and their main material is based on polyvinyl alcohol (PVA), which induces calcification and inflammation [19]. Therefore, the aim of this study was to clinically develop an ideal DDS with suitable microspheres (in terms of material and size) for TACE.

Gellan gum (GG) is a linear, anionic extracellular polysaccharide with repeating tetrasaccharide units of D-glucose, D-glucuronic acid, D-glucose and L-rhamnose sourced from Pseudomonas elodea. Gellan gum is a food additive that functions as a stabilizer, thickening agent and a versatile structuring and gelling agent in a wide variety of foods. Gellan gum has been investigated as a candidate material for biomedical engineering because of its biocompatibility and low cytotoxicity. In our previous studies, we verified the chemical and biological characteristics of gellan gum and identified it as a suitable starting point for developing implantable biomedical devices [20,21]. In the present experiment, we adopted gellan gum as the substrate for developing a microspherical embolization agent. Gellan gum was formed into microspheres via emulsification [22]. In this study, we developed long-term, biodegradable microspheres that encapsulate nanosized graphene carrying chemotherapy drugs to embolize the hepatic artery and achieve dual release. Here, gellan gum (GG) was used as the main material of the microsphere due to its biocompatibility as well as its proven suitability as an embolic agent in terms of slow swelling and degradation [23,24]. Moreover, the application of amine-functionalized graphene oxide (AFGO) improved the reaction with polymers and drugs $[25,26]$. Doxorubicin (Dox) is the main chemotherapeutic drug currently used for liver cancer treatment. The microsphere-encapsulated nanoparticles were synthesized via emulsion to form a GG/AFGO-Dox dual-release system. Its successful generation was confirmed by systemic analysis of its morphology, drug release kinetics, and in vitro and in vivo efficacy in terms of embolization.

\section{Materials and Methods}

\subsection{Materials}

Gelzan $^{\mathrm{TM}} \mathrm{CM}$, calcium chloride, mineral oil, doxorubicin hydrochloride (Dox-HCl) and $\operatorname{Span}^{\circledR} 85$ were purchased from Sigma-Aldrich (St. Louis, MO, USA). Gibco ${ }^{\mathrm{TM}}$ DMEM, Gib-co $^{\mathrm{TM}}$ Fetal Bovine Serum (FBS), Gibco ${ }^{\mathrm{TM}}$ Penicillin-Streptomycin, Invitrogen ${ }^{\mathrm{TM}}$ PrestoBlue $^{\mathrm{TM}}$ Cell Viability Reagent and Gibco ${ }^{\mathrm{TM}}$ Trypsin-EDTA (0.05\%) were purchased from Thermo Fisher Scientific (Branchburg, NJ, USA). FITC Annexin V Apoptosis Detection Kit I was purchased from BD Pharmingen ${ }^{\mathrm{TM}}$ (San Diego, CA, USA). Sodium Nitrate, hydrogen peroxide and Sodium acetate were purchased from HAYASHI PURE CHEMICAL IND. (Osaka, Japan), Ltd. (HPC). Sulfuric Acid was purchased from UNION CHEMICAL WORKS Ltd. (Hsinchu, Taiwan). Potassium permanganate and ferric chloride were 
purchased from SHIMAKYU'S PURE CHEMICALS (Osaka, Japan). Ethylenediamine was purchased from ACROS Organics ${ }^{\mathrm{TM}}$ (Carlsbad, CA, USA). Ethylene glycol was purchased from PanReac AppliChem (Chicago, IL, USA). Graphite powder was donated from the Department of Public Health (Taichung, Taiwan), Chung Shan Medical University. All the samples in this study were sterilized in $70 \%(v / v)$ ethanol solution at $25^{\circ} \mathrm{C}$ for $24 \mathrm{~h}$. Next, samples were washed three times in sterile phosphate buffered saline (PBS) for five minutes each time. Finally, samples were dried or used directly for testing.

\subsection{Amine-Functionalized Graphene Oxide (AFGO) Synthesis}

Amine-functionalized graphene oxide (AFGO) was obtained from graphene oxide (GO). GO was prepared by Hammer's method. Briefly, $4 \mathrm{~g}$ graphite powder was mixed with $2 \mathrm{~g} \mathrm{NaNO}_{3}$ and $92 \mathrm{~mL} \mathrm{H}_{2} \mathrm{SO}_{4}$ and then the mixture was stirred at $4{ }^{\circ} \mathrm{C}$ for $5 \mathrm{~min}$. Next, $12 \mathrm{~g} \mathrm{KMnO}_{4}$ was added at room temperature and stirred for $5 \mathrm{~min}$ and then heated to $35^{\circ} \mathrm{C}$ for $30 \mathrm{~min}$. Then, $184 \mathrm{~mL}$ deionized water was added in the mixture at $65-75^{\circ} \mathrm{C}$ for $15 \mathrm{~min}$. Finally, hydrogen peroxide solution $\left(\mathrm{H}_{2} \mathrm{O}_{2}, 3 \%\right.$ in water) was added for $1 \mathrm{~h}$. After the mixture was centrifuged at $2000 \times g$ for $10 \mathrm{~min}$ to remove the excess $\mathrm{H}_{2} \mathrm{O}_{2}$ and washed 3 times with $\mathrm{ddH}_{2} \mathrm{O}$, it was dried at $60^{\circ} \mathrm{C}$ for 4 days. The $0.5 \mathrm{~g} \mathrm{GO}$ was mixed with $1 \mathrm{~g}$ Iron (III) chloride $\left(\mathrm{FeCl}_{3}\right), 3 \mathrm{~g}$ sodium acetate $\left(\mathrm{C}_{2} \mathrm{H}_{3} \mathrm{NaO}_{2}\right), 20 \mathrm{~mL}$ ethylene glycol $\left(\mathrm{C}_{2} \mathrm{H}_{6} \mathrm{O}_{2}\right)$ and $10 \mathrm{~mL}$ ethylenediamine $\left(\mathrm{C}_{2} \mathrm{H}_{8} \mathrm{~N}_{2}\right)$ in an autoclave at $200{ }^{\circ} \mathrm{C}$ for $2 \mathrm{~h}$. The mixture was washed with deionized water at $2000 \times g$ for $10 \mathrm{~min}$ and it was dried at $60^{\circ} \mathrm{C}$ for 1 day.

\subsection{Preparation of Gellan Gum (GG), GG/AFGO and GG/AFGO-Dox Microsphere}

The gellan gum (GG) microsphere was prepared by an emulsification and cationinduced cross-linking process [22]. The aqueous GG $(0.3 \% w / v)$ solution was stirred for $15 \mathrm{~min}$ at $85-90^{\circ} \mathrm{C}$ and then AFGO $(0.1 \% w / v)$ was added in GG transparent solution by ultrasound for $1 \mathrm{~h}$. The mineral oil $(90 \% w / w)$ was slowly mixed with GG/AFGO $(10 \%$ $w / w$ ) heated at $50{ }^{\circ} \mathrm{C}$ by water-in-oil emulsion using a 23G homogenizer (400 rpm) blender for $10 \mathrm{~min}$. Then, Span $85(0.5 \% \mathrm{w} / v)$ and $\mathrm{CaCl}_{2}(10 \mathrm{~mL}, 1.25 \%)$ were added and kept stirring at $50{ }^{\circ} \mathrm{C}$ for $1 \mathrm{~h}$. After that, $\mathrm{CaCl}_{2}(10 \mathrm{~mL}, 1.25 \%)$ was added again for $10 \mathrm{~min}$. GG/AFGO microspheres were separated into different size fractions by sieving using 25-mesh $(710 \mu \mathrm{m}), 40$-mesh $(425 \mu \mathrm{m}), 50$-mesh $(300 \mu \mathrm{m})$ and 70 -mesh $(212 \mu \mathrm{m})$ standard sieves. The microsphere used the acetone to wash three times and was re-dispersed in deionized water. In another experiment, the $\operatorname{AFGO}(0.1 \% w / v)$ was added to $2 \mathrm{mg}$ Dox in $10 \mathrm{~mL}$ deionized water for 3 days. The synthesis of GG/AFGO-Dox microsphere was conducted by the emulsification process using the hydrophilic phase containing GG mixed AFGO-Dox solution $(10 \% w / w)$ with the hydrophobic phase (mineral oil, $90 \% w / w)$ and all the other parameters remained the same, respectively.

\subsection{Characterization of GO, AFGO, GG/AFGO Microsphere and GG/AFGO-Dox Microsphere}

The zeta potential and chemical state of the $\mathrm{GO}(1 \mathrm{mg} / \mathrm{mL}$ in deionized water, room temperature) and AFGO (1 mg/mL in deionized water, room temperature) were analyzed by a zeta potential analyzer (Mastersizer 2000, Malvern, UK) and fourier transform infrared spectroscopy (FTIR) (Tensor 27). The particle size of the AFGO, GG microsphere and GG/AFGO-Dox microsphere was measured by a laser diffraction particle size analyzer (Coulter LS230 and Mastersizer 2000, Malvern, UK). The morphology of the GG/AFGO microsphere and GG/AFGO-Dox microsphere were characterized by SEM (Jeol JSM-6400, Tokyo, Japan). The elemental composition was performed by energy-dispersive $\mathrm{X}$-ray spectroscopy (EDS).

\subsection{Release and Kinetic Model of AFGO and DOX in GG/AFGO-Dox Microsphere}

The standard curve of AFGO concentration was created by counting the number of AFGO in different concentrations using the counter, because the particle size of AFGO is concentrated. The amount AFGO and DOX released from different sizes of GG/AFGO and GG/AFGO-Dox microsphere was calculated in $15 \mathrm{~mL}$ centrifuge tubes. The GG/AFGO 
microsphere $(1 \mathrm{mg} / \mathrm{mL})$ was immersed in $5 \mathrm{~mL}$ of phosphate $(1 \mathrm{M}, \mathrm{pH} 7.4)$ and incubated at $37^{\circ} \mathrm{C}$ with shaking for 45 days. The sample was centrifuged at $300 \times g$ for $10 \mathrm{~min}$ and the supernatant was taken to calculate the concentration of AFGO every four days. In another experiment. The GG/AFGO-Dox microsphere $(1 \mathrm{mg} / \mathrm{mL})$ was immersed in $2 \mathrm{~mL}$ of phosphate $(1 \mathrm{M}, \mathrm{pH} 7.4)$ and incubated at $37^{\circ} \mathrm{C}$ with shaking for 45 days. The sample was centrifuged at $350 \times g$ for $10 \mathrm{~min}$ and the supernatant was taken to measure the Dox concentration by spectrophotometry at $480 \mathrm{~nm}$ every four days. Five kinetic models-Zero, First, Higuchi, Hixson-Crowell and Korsmeyer-Peppas-were used.

\subsection{HepG2 Uptake of AFGO}

Human hepatoma cells (HepG2) were used as the model cell line for evaluation of uptake of AFGO nanoparticles. Cells were obtained from the Bioresource Collection and Research Center (BCRC), Hsinchu, Taiwan. The cells were grown on EMEM containing $1 \mathrm{mM}$ sodium pyruvate supplemented with $10 \%$ fetal bovine serum and $40 \mathrm{mg} / \mathrm{mL}$ gentamycin, at $37^{\circ} \mathrm{C}$. Cells were trypsinized on reaching $90 \%$ confluence. HepG2 cells were seeded on glass coverslips and allowed to adhere by incubating for a period of $24 \mathrm{~h}$ at $37^{\circ} \mathrm{C}$. The medium was discarded and replaced with AFGO nanoparticle medium (experimental group) and without AFGO nanoparticles medium (control). The glass coverslips were. then incubated at $37^{\circ} \mathrm{C}$ for 3,9 and $24 \mathrm{~h}$. Then, we washed the glass coverslips with cold PBS three times to remove the excess nanoparticles not taken up by the cells and then fixed the cell with $1 \%$ glutaraldehyde. In order to remove residue nanoparticles completely, we used ultrasonic equipment to clean the glass coverslips again. The cells were viewed under the inverted fuorescence microscope (Zeiss Axi-oskop 2, Carl Zeiss Inc., Oberkochen, Germany).

\subsection{In Vitro Cell Viability and Apoptosis Assay}

HepG2 were seeded at $3 \times 104$ cells per well in the 96-well plate. The cells were incubated with various concentrations of Dox $(0,1.57,2.35,3.17 \mu \mathrm{M})$ and $\operatorname{AFGO}(0,25,50$, $75 \mu \mathrm{g} / \mathrm{mL}$ ) for $24 \mathrm{~h}$. The cell viability was determined using the Presto reagent method according to the manufacturer's protocol. In this study, the dose of Dox and AFGO were approximate to the cumulative release concentrations from GG/AFGO-Dox microspheres over 28 days. For cell apoptosis assays, HepG2 cells were seeded in 6-well plates at $4 \times 10^{5}$ cells per well for $24 \mathrm{~h}$. The cells were incubated with various concentrations of Dox and AFGO. After $24 \mathrm{~h}$ incubation, cells were harvested by trypsin-EDTA and incubated in $100 \mathrm{~mL} 1 \mathrm{X}$ buffer, followed by staining with FITC Annexin V (5 mL) and Propidium Iodide Staining Solution ( $5 \mathrm{~mL}$ ) according to FITC Annexin V Apoptosis Detection Kit I with FITC Annexin V and Propidium Iodide Staining Solution. After incubation at room temperature for $15 \mathrm{~min}$, samples were analyzed on a Flow Cytometer (FACSCalibur).

\subsection{Vessel Embolization of Microsphere In Vivo}

The New Zealand White rabbits were obtained from the Laboratory Animal Center (Taipei, Taiwai) at the weight of $2.6-3 \mathrm{~kg}$. Before administration, the hairs of ear veins were removed. The Zoletil (Virbac) / Xylazine (20-40 mg/kg Z + 5-10 mg/ kg X) was injected into the rabbit. Then, the GG/AFGO-DOX microsphere $(20 \mathrm{mg} / \mathrm{mL})$ was injected into the proximal part of the ear vein $(0.15 \mathrm{~mL} /$ ear). After administration for $0,4,8,12$ days, the chemoembolization effect was carefully evaluated by color and shapes of rabbits' ears. Ethics statement concerning animal work-the authors confirm that all experiments were performed in accordance with relevant guidelines and regulations. Animal work methods were carried out in accordance with procedures that were approved by the IACUC (Approval NO 2147: Vaild from 1 October 2019 to 31 July 2022) of the Chung-Shan Medical University Experimental Animal Center. 


\subsection{Statistical Analysis}

All experiments were repeated at least 3 times and the Student's test was performed to evaluate the difference in the average between groups. A value of ${ }^{*} p<0.05,{ }^{* *} p<0.01$ and ${ }^{* * *} p<0.01$ was taken as significant (Statistical Analysis: Microsoft Excel 2013).

\section{Results and Discussion}

3.1. Synthesis and Characterization of Amine-Functionalized Graphene Oxide (AFGO) and Amine-Functionalized Graphene Oxide-Doxorubicin (AFGO-Dox)

Dual-function microspheres that encapsulated a nanocarrier with an embolic agent (GG/AFGO-Dox) were developed for transcatheter arterial chemoembolization (TACE) to block nutrient delivery and enhance drug absorption, leading to tumor cell starvation and subsequent cell apoptosis (Figure 1). Many reports have highlighted the potential of graphene oxide (GO) to function as a drug carrier due to its potential $\pi-\pi$ and hydrophobic interactions with drugs that have aromatic rings [27,28]. In addition, amine-functionalized graphene oxide (AFGO) was further modified to enhance drug hydrophilic interactions and to facilitate graphene assembly with the polymer. A GO size of between 0.5 and $25 \mu \mathrm{m}$ enables cell membrane penetration, thereby increasing drug availability [29].

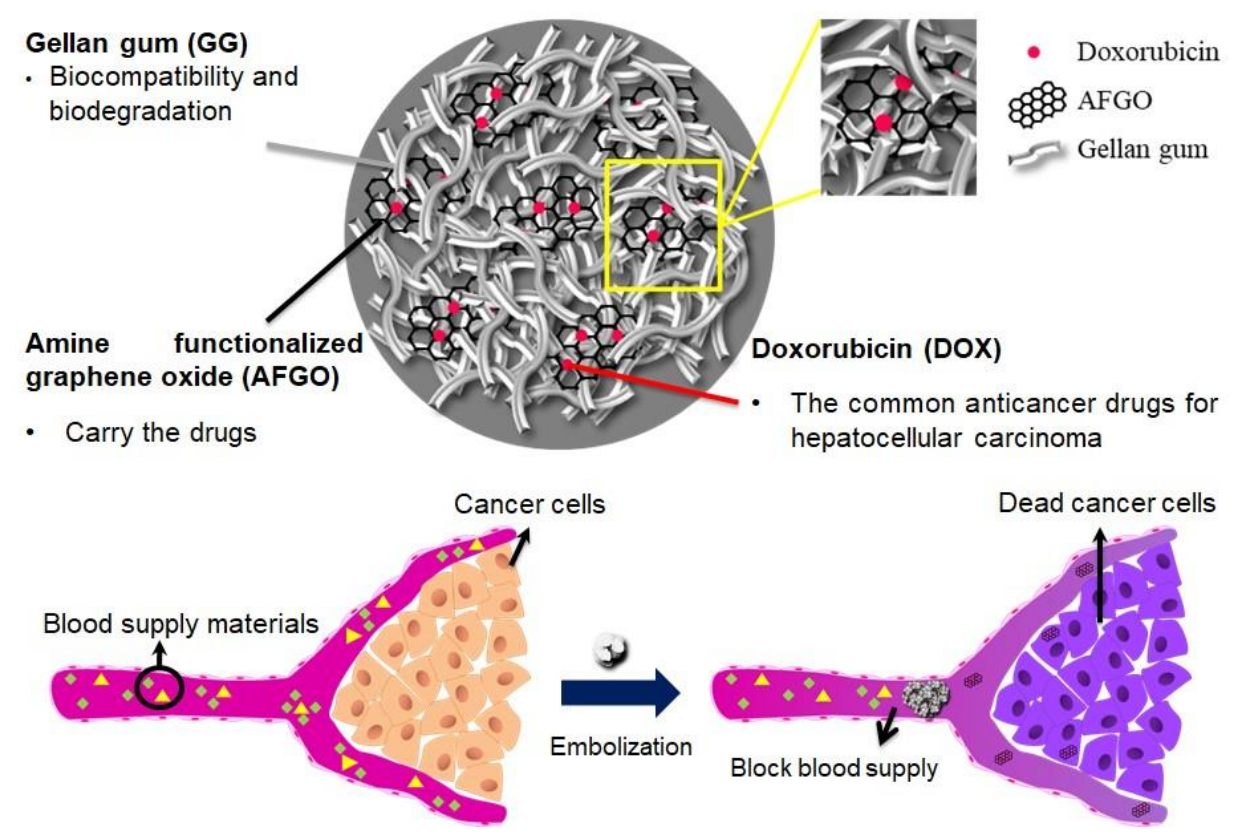

Figure 1. Scheme showing the embolic agent of microsphere-nanoparticle GG/AFGO-DOX blocking the blood supply and delivering AFGO-DOX in cancer treatment.

Following the modification of GO, the structure of AFGO was analyzed using FTIR spectroscopy and EDS to confirm it was successfully prepared. In accordance with Yao, S.Z. et al. (2013) [30], as shown in Figure 2A, the peak at $1712 \mathrm{~cm}^{-1}$ was replaced with a new peak at $1163 \mathrm{~cm}^{-1}$, representing $\mathrm{C}-\mathrm{N}$ binding [31]. The amine group produced a peak at $667 \mathrm{~cm}^{-1}$. Moreover, the amount of nitrogen in AFGO was $6.57 \%$ and the size of AFGO was $1.564 \pm 0.414 \mu \mathrm{m}$, as shown in Figure 2B,C. In addition, the zeta potentials of GO and AFGO were -25.4 and $-11.5 \mathrm{mV}$, respectively, as shown in Figure 2D. The negative zeta potential of GO was supposedly due to the negatively charged surface of the GO sheet, which is attributed to the presence of carboxyl groups, whereas the relatively more positive zeta potential of the AFGO nanosheets was attributed to the positive charges that were induced by the presence of the $\mathrm{NH}_{2}$ groups. Additionally, AFGO that is dispersed in deionised water ( $\mathrm{pH}$ 5.5) presents a weak negative charge. According to Fang et al. [32], the zeta potential of AFGO varies depending on the $\mathrm{pH}$ value, being positive at $\mathrm{pH}<4$, and negative at $\mathrm{pH}>4$. To enhance the therapeutic efficiency of Dox, it 
was conjugated to AFGO via electrostatic and $\pi-\pi$ interactions (AFGO-Dox complex). As shown in Figure 2D, the zeta potentials of Dox- $\mathrm{HCl}$ and AFGO-Dox were $-10.9 \mathrm{mV}$ and $+36.2 \mathrm{mV}$, respectively. The DOX $-\mathrm{HCl}$ (negative) is a product of the interaction between an acid and a base, whereby doxorubicin acts as a weak base and $\mathrm{HCl}$ is an acid. Upon mixing Dox- $\mathrm{HCl}$ and AFGO in water, $\mathrm{HCl}$ dissociates into $\mathrm{H}^{+}$and $\mathrm{Cl}^{-}$and the $\mathrm{pH}$ decreases ( $\mathrm{pH}$ 4.0). In addition, AFGO-Dox complex with the former leading to the protonation of $\mathrm{N}$ in doxorubicin, thus establishing a positive charge. The AFGO-Dox complex exhibited a positive charge also due to the presence of the amine group, thus confirming that Dox was chemical bonder with the AFGO nanoparticle. These results illustrate the potential for successfully synthesized AFGO-Dox to penetrate the cell membrane and act as a drug carrier through electrostatic interactions.

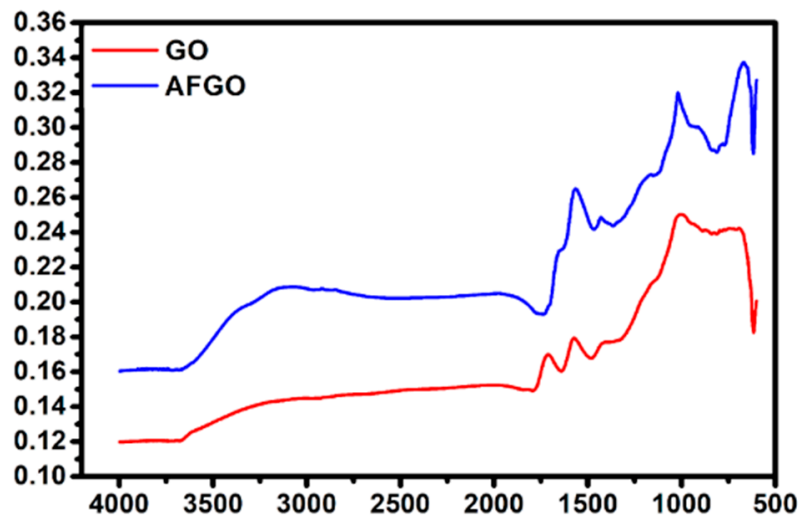

(A)

Size Distribution by Intensity

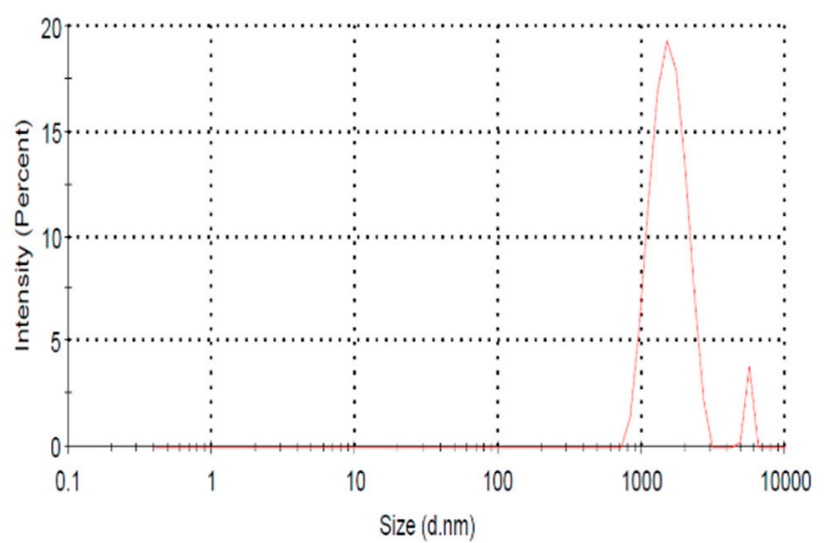

(C)

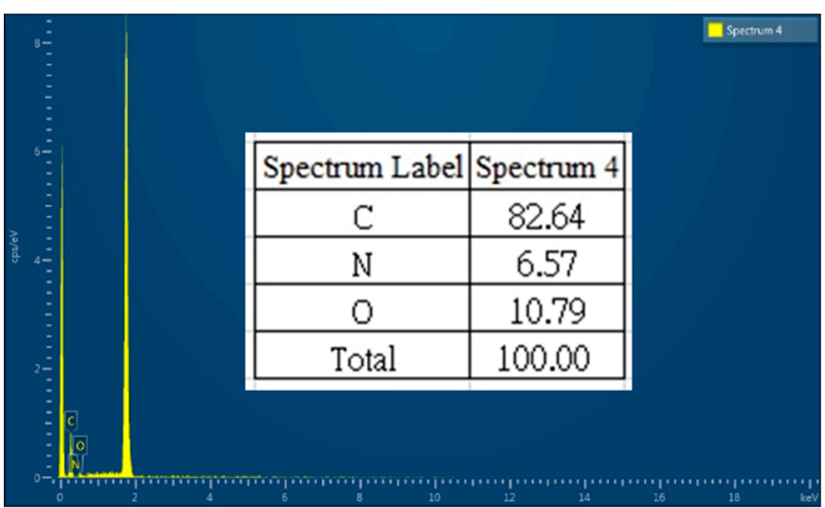

(B)

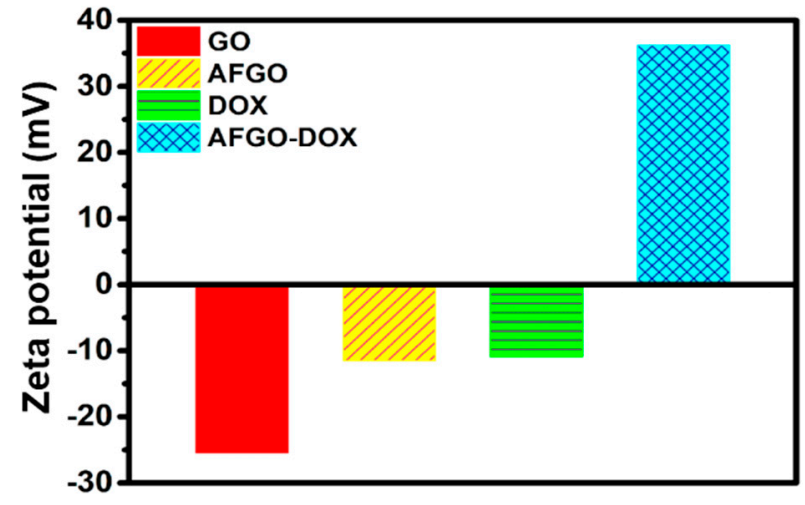

(D)

Figure 2. (A) FTIR spectrum of GO (red) and AFGO (blue). (B) EDS analysis of AFGO. (C) Size distribution of AFGO was evaluated using a laser diffraction particle size analyzer. (D) Zeta potentials of GO, AFGO, DOX and AFGO-DOX.

\subsection{Synthesis and Characterization of GG and GG/AFGO-Dox Microspheres}

For the TACE procedure, blocking the blood supply closest to the tumor site is important for reducing the damage to normal cells. Therefore, it is essential that the embolic microsphere has a suitable diameter for TACE, which is based on blood vessel size. The size of microspheres used for TACE in clinical trials has ranged from 50 to $500 \mu \mathrm{m}$ [33]. To evaluate the size variation in the GG and GG/AFGO-Dox microspheres, their diameter was measured using a laser diffraction particle size analyzer. A mixture of GG and GG/AFGO-Dox microspheres was filtered using 25, 40, 50 and 70 mesh sieves, thereby separating the microspheres on the basis of diameter. As shown in Figure 3A, the 25-mesh sieve was able to separate GG $(620 \pm 44 \mu \mathrm{m})$ and GG/AFGO-Dox $(674 \pm 43 \mu \mathrm{m})$ micro- 
spheres that were over $500 \mu \mathrm{m}$ in size, where-as the 40,50 and 70 mesh sieves yielded GG microspheres of $485 \pm 28,371 \pm 20$ and $250 \pm 17 \mu \mathrm{m}$ and GG/AFGO-Dox microspheres of $498 \pm 25,359 \pm 19$ and $226 \pm 15 \mu \mathrm{m}$, respectively. Following the addition of AFGO, the sizes of the GG/AFGO-Dox and GG microspheres were similar. To confirm the encapsulation of AFGO-Dox, we analyzed the morphology of the microspheres using SEM. The SEM images in Figure 3B, C show the elliptical morphology and smooth and compact surface of the GG microspheres. This round shape is very important to allow an effective ischemic effect for TACE of cancer. Furthermore, the internal structure of the GG particles can clearly be seen as a loose and fibrous structure. On the other hand, the GG/AFGO-Dox microspheres were spherical, with a network structure on their surface, as shown in Figure 3D. Moreover, the internal structure of the GG/AFGO-Dox particles was tight, as shown in Figure 3E. This dense structure was formed by the entanglement of the GG and AFGO sheets. These results confirmed the free and AFGO-Dox-loaded gellan gum microcapsules were not changed for their size distribution and morphology.

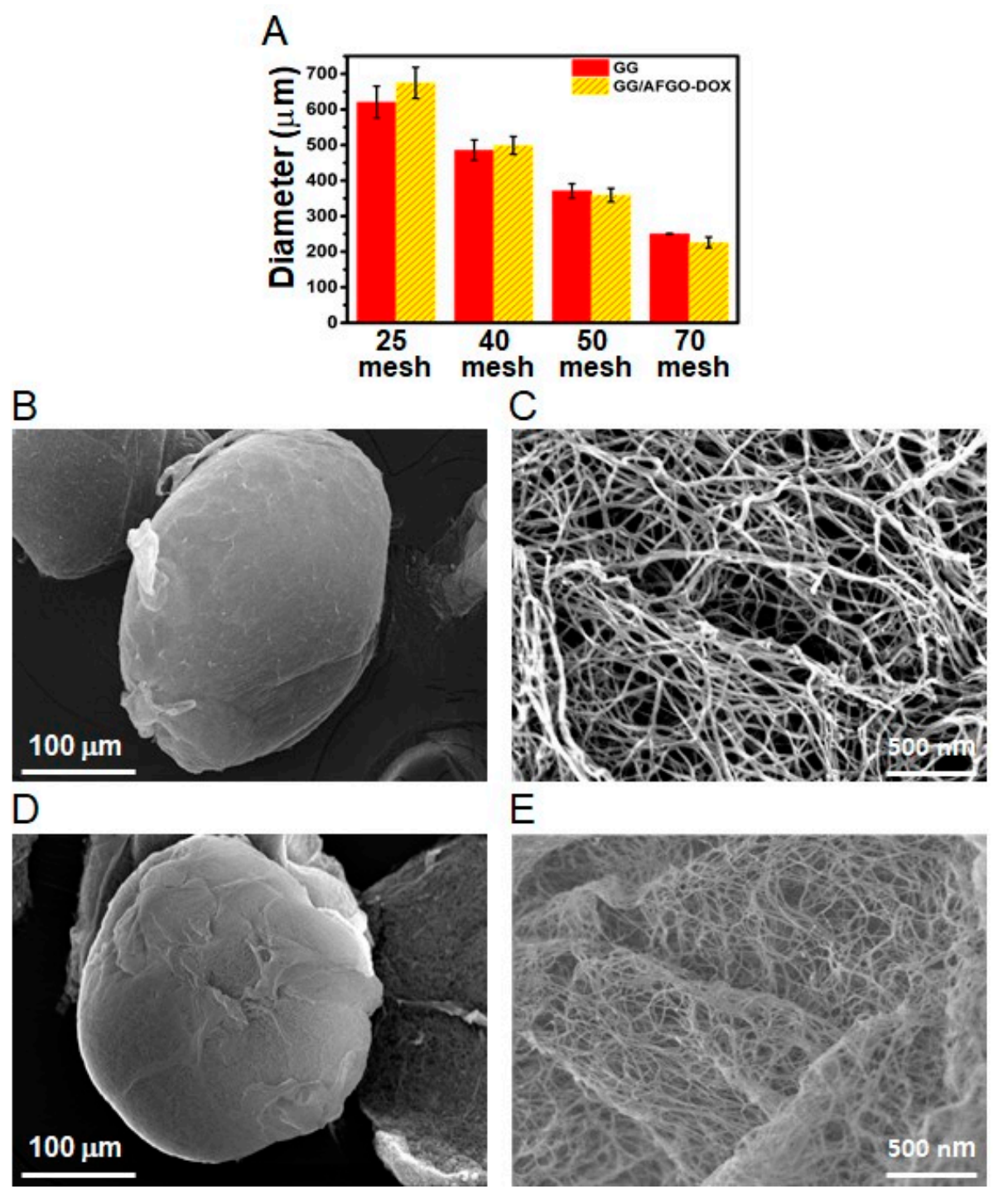

Figure 3. (A) Size distribution of GG and GG/AFGO-Dox following separation using 25, 40, 50, and 70 mesh sieves, and their evaluation using a laser diffraction particle size analyzer. SEM images of GG (B) surface and (C) inner microsphere. SEM images of GG/AFGO-DOX (D) surface and (E) inner microsphere. 


\subsection{AFGO and Dox Release and Kinetic Model in GG/AFGO-Dox Microspheres}

Many studies have determined the concentration of AFGO using a spectrophotometer; however, AFGO was not water-soluble in this study $[34,35]$. Therefore, this study determined the concentration of AFGO by using a microscope to count the number of molecules. As shown in Figure $4 \mathrm{~A}$, the $R$ value of the standard curve was credible (0.99). To improve the efficiency of AFGO-Dox cancer cell entry, the release and kinetic mechanisms of AFGO encapsulated in the large (GG/AFGO-Dox-1 $(674 \pm 43 \mu \mathrm{m})$ ) and small (GG/AFGO-Dox-2 $(226 \pm 15 \mu \mathrm{m}))$ microspheres were analyzed. As shown in Figure $4 \mathrm{~B}$, the cumulative release concentrations of GG/AFGO-Dox-1 and GG/AFGO-Dox-2 over 28 days were 4 and $6 \mu \mathrm{g} / \mathrm{mg}$ microspheres, respectively. The higher release concentration of the latter was due to its greater number of microspheres per unit weight. However, their release slopes were similar due to the structures of the microspheres being identical. Moreover, their release over 14 to 28 days was faster than their release over 0 to 14 days because of the slow degradation of GG.
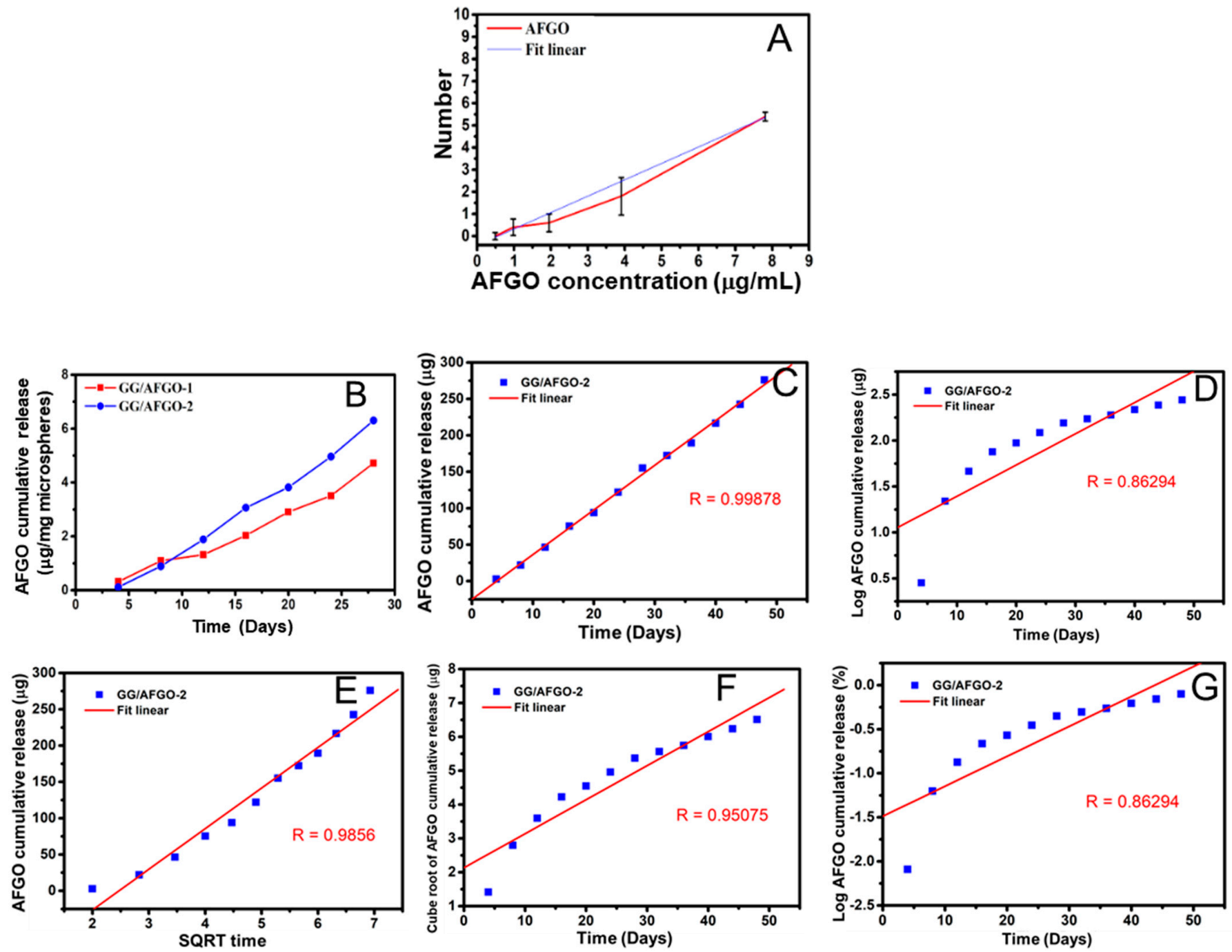

Figure 4. (A) Profile of AFGO release (B) Profile of AFGO release from GG/AFGO-Dox-1 (674 $\pm 43 \mu \mathrm{m})$ and GG/AFGO-Dox-2 $(226 \pm 15 \mu \mathrm{m})$ over 28 days. AFGO release according to the following kinetic models: (C) zero, (D) first, (E) Higuchi, (F) Hixson-Crowell and (G) Korsmeyer-Peppas.

Five drug release kinetic models were used to evaluate the AFGO release from the GG/AFGO-Dox-2 microspheres: zero-order, first-order, Higuchi, Hixson-Crowell and Korsmeyer-Peppas [36,37]. The $R$ values that were obtained for each model were 0.9988 , 
$0.8629,0.9856,0.9508$ and 0.8629 , respectively, as shown in Figure 4C-G. The best fits were obtained using the zero-order and Higuchi models. The former suggested that the GG/AFGO-Dox-2 microspheres were not degraded and AFGO was released slowly and steadily, whereas the latter suggested that the GG/AFGO-Dox-2 microspheres were degraded over time, leading to a loose structure, thereby facilitating the penetration of AFGO into GG. Considering that GG is a slowly degrading material, the kinetics of AFGO release from the GG/AFGO-Dox-2 microspheres was best described by the Higuchi model. Furthermore, the introduction of AFGO improved the stability of the gellan gum particles, rendering them akin to a steel ball, thereby also satisfying the zero-order model. Overall, these results indicate that the GG/AFGO-Dox microspheres roughly exist in the form of steel balls, which prevents the substantial release of AFGO in a short period of time while simultaneously achieving embolization and chemotherapy. Furthermore, the embolization is only temporary due to the slow degradation of the embolic agent.

We sought to determine the effect of the microsphere diameter on Dox release using kinetic models. The cumulative release concentrations of Dox from GG/AFGO-Dox-1 and GG/AFGO-Dox-2 were 2.31 and $1.18 \mu \mathrm{g} / \mathrm{mg}$ microspheres, respectively, over 28 days, as shown in Figure 5A. The difference in concentration was due to the latter having a larger surface area per unit weight. Once again, five kinetic models were used to analyze Dox release from the GG/AFGO-Dox-2 microspheres: zero-order, first-order, Higuchi, Hixson-Crowell and Korsmeyer-Peppas. The $R$ values obtained for each model were $0.9302,0.8054,0.9770,0.9314$ and 0.8054 , respectively, as shown in Figure 5B-E. The drug release results best conformed to the Higuchi model, in which drug release is characterized by proceeding through diffusion, a structure with varying geometric shapes or matrix characteristics (e.g., porosity), and a release rate that is dependent on the material thickness [38]. These characteristics indicate that Dox was initially released from the surface and then from the inner layer, thus achieving slow release through continuous diffusion. The kinetic models of AFGO and Dox release were consistent with their encapsulation.

\subsection{Verification of the Cellular Uptake of AFGO}

The particle size analysis of AFGO (Figure 2C) revealed that the size of graphene should enable cell membrane penetration. To verify this possibility, a time course of AFGO absorption by the HepG2 cells was investigated through microscopy analysis at 3, 9 and $24 \mathrm{~h}$, as shown in Figure 6. The level of AFGO that was phagocytosed into the cell increased with time, thus showing that AFGO was able to penetrate into the HepG2 cells.

\subsection{Cell Viability and Apoptosis of GG/AFGO-Dox}

Embolic agents mainly block the blood supply, resulting in starvation; however, they do not react directly with the tumor cells. Therefore, we sought to test the cytotoxicity of DOX and AFGO on HepG2 cells by the Presto reagent method and it was found that Dox and AFGO were toxic to HepG2 cells dose-dependently. The IC50 of doxorubicin in HepG2 cell is $1.1 \mu \mathrm{M} / \mathrm{mL}$ [22]. The experimental results showed that the amount of released doxorubicin from 226, 359 and $498 \mu \mathrm{m}$ GG/ AFGO-DOX microspheres was approximately 1.4-, 2.1- and 2.9-fold above the IC50 value. On the basis of the results observed, we assert that three sizes of multifunctional GG/AFGO-DOX microspheres prepared in this study meet the requirements of TACE applications. In addition, graphene oxide particles with ammonia modification (AFGO), tend to aggregate into cell culture which influences their effective size and may affect their induced cytotoxicity [39]. Therefore, at higher concentrations of AFGO, aggregation was much more pronounced and the toxicity increased. Moreover, we examined whether Dox induced apoptosis using the FITC Annexin V Apoptosis Detection Kit I. As shown in Figure 7B, the apoptosis rates were 17.57\%, 21.35\%, 28.59\% and 34.16\% for the control, Dox 1.57, 2.35, 3.17 $\mu \mathrm{M}$ treatments, respectively. Different concentrations of AFGO treatments induced significant apoptosis compared with the control, as shown in Figure 7C. Therefore, AFGO was able to increase the cytotoxic effect of Dox, in addition to inducing cell death. Park et al. [40] found that graphene oxide, reduced graphene 
oxide and sodium lauryl sulfate graphene oxide at concentrations of 3-25 $\mu \mathrm{g} / \mathrm{mL}$ induced mild cytotoxicity of A549 cells, whereas concentrations of 50-400 $\mu \mathrm{g} / \mathrm{mL}$ induced severe cytotoxicity [41,42]. To illustrate the cytotoxicity of AFGO, different concentrations were investigated in vitro. As shown in Figure 7D, the cell viabilities were reduced to $19 \%, 22 \%$ and 39\% following treatment with 25 (AFGO-1), 50 (AFGO-2) and 75 (AFGO-3) $\mu \mathrm{g} / \mathrm{mL}$, respectively. All concentrations exhibited significant cytotoxicity compared to the control group, in line with the previous report, although the cell line used and the graphene modification were different. Furthermore, the level of induced apoptosis was used to evaluate the effect of different concentrations of AFGO on liver cancer cells. As shown in Figure 7E, the apoptosis rates were $25.19 \%, 27.38 \%, 41.85 \%$ and $41.51 \%$ for the control, AFGO-1, AFGO-2 and AFGO-3 reactions, respectively. All three concentrations of AFGO induced significant apoptosis compared with the control, as shown in Figure 7F. These results indicate that AFGO was toxic toward HepG2 cells at concentrations over $25 \mu \mathrm{g} / \mathrm{mL}$.
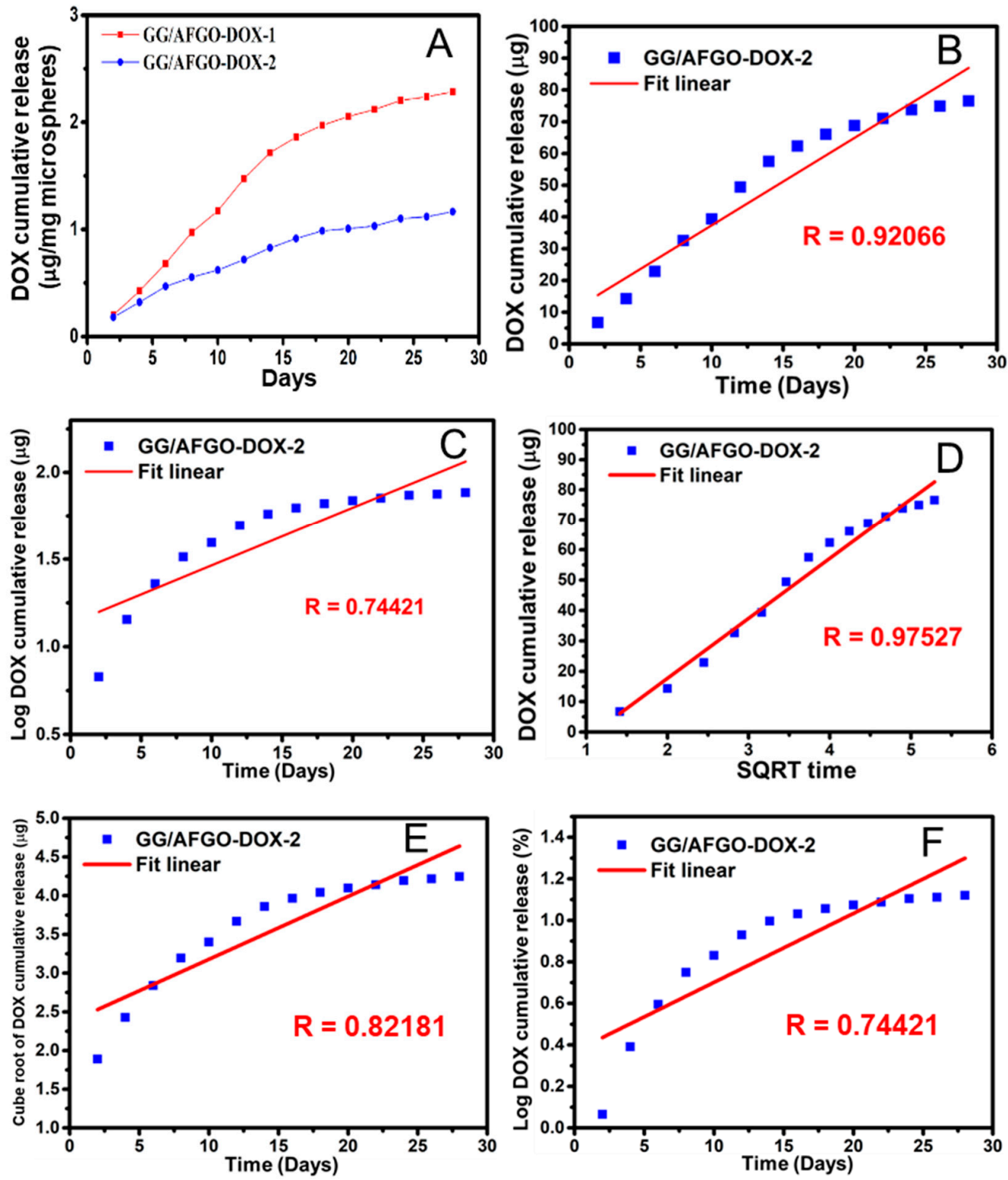

Figure 5. (A) Profile of Dox release from the GG/AFGO-Dox-1 (674 $\pm 43 \mu \mathrm{m})$ and GG/AFGO-Dox-2 $(226 \pm 15 \mu \mathrm{m})$ over 28 days. Dox release according to the following kinetic models: (B) zero, (C) first, (D) Higuchi, (E) Hixson-Crowell, and (F) Korsmeyer-Peppas. 

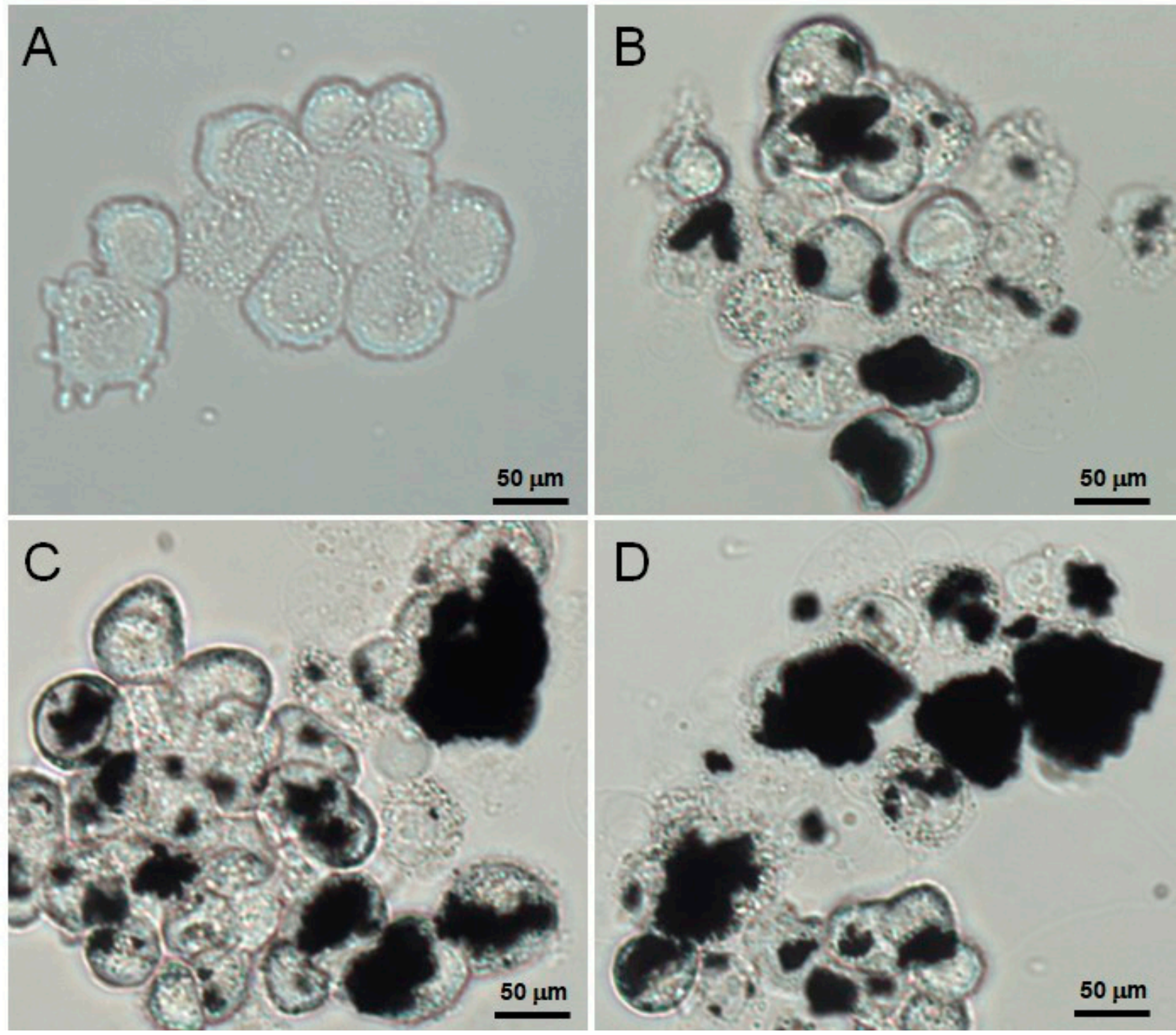

Figure 6. Uptake of AFGO by HepG2 cells observed with a microscope at (A) $0 \mathrm{~h}$, (B) $3 \mathrm{~h}$, (C) $9 \mathrm{~h}$ and (D) $24 \mathrm{~h}$ (scale bar $=50 \mu \mathrm{m} ; 400 \times)$.

\subsection{Vessel Embolization of GG/AFGO In Vivo}

To evaluate the embolization efficiency of GG/AFGO-Dox $(226 \mu \mathrm{m})$ in vivo, we used a rabbit ear model that had been established in our previous study [22]. As shown in Figure 8, following the injection of GG/AFGO-Dox microspheres, the central auricular artery and its branches were visible in the ear (Figure 8A, day 0). Six days after embolization (Figure 8B), the blood flow at the tip of the ear was blocked. In addition, there was no obvious edema or inflammation, thus confirming the good biocompatibility of GG/AFGO-Dox microspheres. Twelve days after embolization (Figure 8C), the branches of the artery between the injection site and the tip of the ear were occluded, resulting in ischemic necrosis. These results indicate that the GG/AFGO-Dox microspheres successfully achieved embolization. 

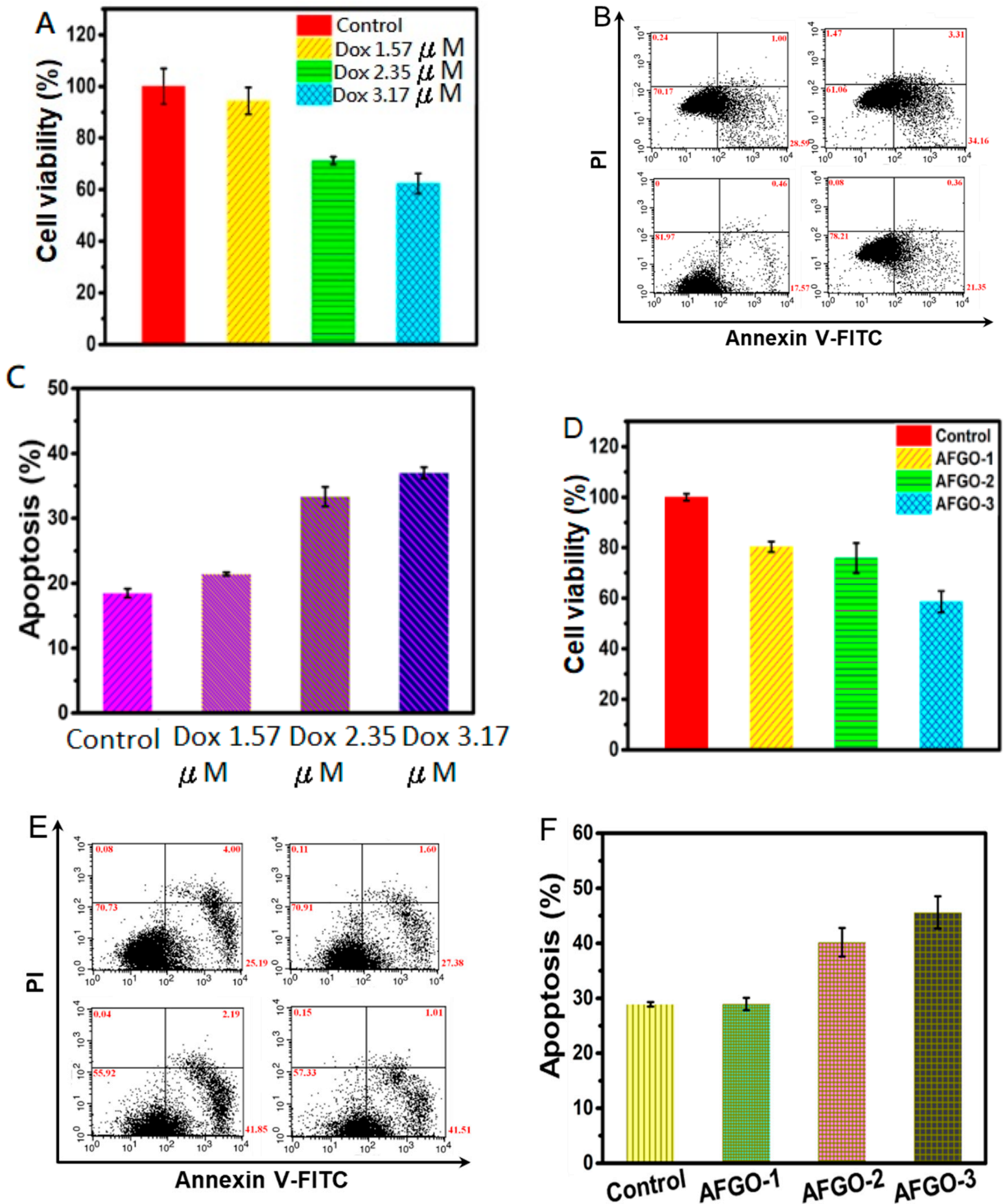

Figure 7. Analysis of cell viability and apoptosis by flow cytometry. (A) Cell viability of HepG2 cells after $24 \mathrm{~h}$ incubation in medium with 0 (control), 1.57, 2.35, $3.17 \mu \mathrm{M}$ of DOX. (B,C) Apoptosis induced in HepG2 cells treated with different concentrations of DOX for $24 \mathrm{~h}$ by flow cytometry. (D) Cell viability of HepG2 cells after $24 \mathrm{~h}$ incubation in a medium with AFGO-1 $(25 \mu \mathrm{g} / \mathrm{mL})$, AFGO-2 $(50 \mu \mathrm{g} / \mathrm{mL})$, AFGO-3 $(75 \mu \mathrm{g} / \mathrm{mL})$ and without AFGO (control). (E,F) Apoptosis induced in HepG2 cells treated with AFGO-1 $(25 \mu \mathrm{g} / \mathrm{mL})$, AFGO-2 $(50 \mu \mathrm{g} / \mathrm{mL})$ and AFGO-3 $(75 \mu \mathrm{g} / \mathrm{mL})$ for 24 h by flow cytometry. Two-tailed Student's test was used. 

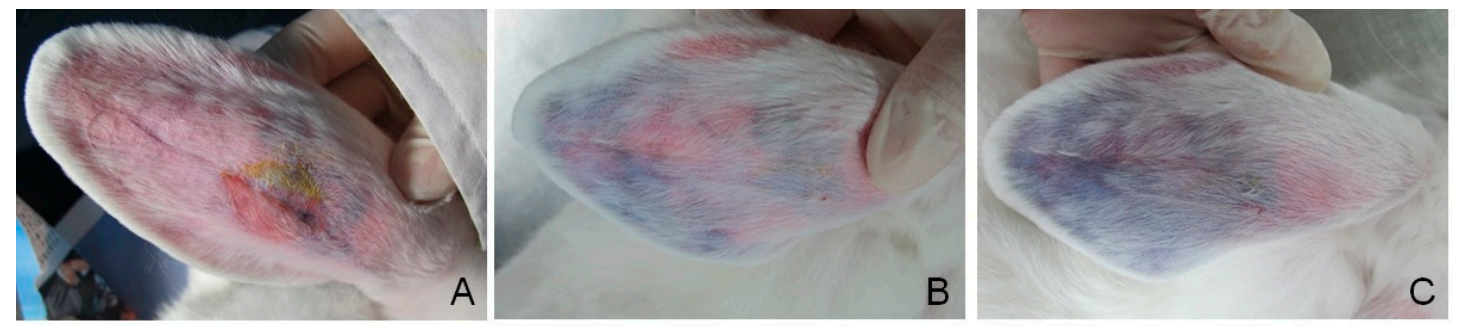

Figure 8. The embolization of GG/AFGO-Dox microspheres using the macroscopic view observed at (A) day 0 , (B) day 6 and (C) day 12.

\section{Conclusions}

In conclusion, embolization agents based on gellan gum polymer were developed. The properties of an embolization agent play an important role in guiding clinical choices. In this study, we used gellan gum to encapsulate a nanosized (AFGO) drug delivery system, yielding GG/AFGO-Dox microspheres of different sizes as a multifunctional embolic agent. The gellan gum-based microspheres are suitable for long-acting vascular embolization with excellent biocompatibility. Furthermore, they effectively improved the stability of doxorubicin, strengthened its affinity toward cancer cells, and increased its availability. In the future, our aim is to provide better embolization agents for the treatment of liver or other cancers using this device.

Author Contributions: H.-W.C.: chemical, structural analytical and pharmaceutical research, methodology, investigation, formal analysis and writing—original draft; Y.-J.H.: methodology, investigation; H.-Y.C.: analytical research, formal analysis; M.-W.L.: conceptualization, chemical, structural, analytical and pharmaceutical research, investigation, writing — original draft, editing and supervision. All authors have read and agreed to the published version of the manuscript.

Funding: The research was funded by the Ministry of Science and Technology in Taiwan, grant number MOST 108-2221-E-040-006-MY3.

Institutional Review Board Statement: Not applicable.

Informed Consent Statement: Not applicable.

Data Availability Statement: The data presented in this study are available on request from the corresponding author.

Conflicts of Interest: The authors declare no conflict of interest.

\section{References}

1. Hare, J.I.; Lammers, T.; Ashford, M.B.; Puri, S.; Stirm, G.; Barry, S.T. Challenges and strategies in anti-cancer nanomedicine development: An industry perspective. Adv. Drug Deliv. Rev. 2017, 108, 25-38. [CrossRef]

2. Voronin, D.V.; Abalymov, A.A.; Svenskaya, Y.I.; Lomova, M.V. Key Points in remote-controlled drug delivery: From the carrier design to clinical trials. Int. J. Mol. Sci. 2021, 22, 9149. [CrossRef]

3. Xia, W.; Tao, Z.; Zhu, B.; Zhang, W.; Liu, C.; Chen, S.; Song, M. Targeted delivery of drugs and genes using polymer nanocarriers for cancer therapy. Int. J. Mol. Sci. 2021, 22, 9118. [CrossRef]

4. Li, C.; Wang, J.; Wang, Y.; Gao, H.; Wei, G.; Huang, Y.; Yu, H.; Gan, Y.; Wang, Y.; Mei, L.; et al. Recent progress in drug delivery. Acta Pharm. Sin. B 2019, 9, 1145-1162. [CrossRef]

5. Stoff, J.A. Selected office based anticancer treatment strategies. J. Clin. Oncol. 2019. [CrossRef]

6. Ahmadpour, S.T.; Desquiret-Dumas, V.; Yikilmaz, U.; Dartier, J.; Domingo, I.; Wetterwald, C.; Orre, C.; Gueguen, N.; Brisson, L.; Mahéo, L.; et al. Doxorubicin-induced autophago lysosome formation is partly prevented by mitochondrial ROS elimination in DOX-resistant breast cancer cells. Int. J. Mol. Sci. 2021, 22, 9283. [CrossRef] [PubMed]

7. Mikušová, V.; Mikuš, P. Advances in chitosan-based nanoparticles for drug delivery. Int. J. Mol. Sci. 2021, 22, 9652. [CrossRef]

8. Sun, T.; Dasgupta, A.; Zhao, Z.; Nurunnabi, M.; Mitragotra, S. Physical triggering strategies for drug delivery. Adv. Drug Deliv. Rev. 2021, 158, 36-62. [CrossRef]

9. Delicque, J.; Guiu, B.; Boulin, M.; Schwanz, H.; Piron, L.; Cassinotto, C. Liver chemoembolization of hepatocellular carcinoma using TANDEM ${ }^{\circledR}$ microspheres. Future Oncol. 2018, 14, 2761-2772. [CrossRef] [PubMed] 
10. Schicho, A.; Pereira, P.L.; Haimerl, M.; Niessen, C.; Michalik, K.; Beyer, L.P.; Stroszczynski, C.; Wiggermann, P. Transarterial chemoembolization (TACE) with degradable starch microspheres (DSM) in hepatocellular carcinoma (HCC): Multi-center results on safety and efficacy. Oncotarget 2017, 8, 72613-72620. [CrossRef] [PubMed]

11. Lammer, J.; Malagari, K.; Vogl, T.; Pilleul, F.; Denys, A.; Watkinson, A.; Pitton, M.; Sergent, G.; Pfammatter, T.; Terraz, S.; et al. Prospective randomized study of doxorubicin-eluting-bead embolization in the treatment of hepatocellular carcinoma: Results of the PRECISION V study. Cardiovasc. Interv. Radiol. 2010, 33, 41-52. [CrossRef] [PubMed]

12. Paul, S.B.; Sharma, H. Role of Transcatheter Intra-arterial Therapies for Hepatocellular Carcinoma. J. Clin. Exp. Hepatol. 2014, 4, S112-S121. [CrossRef]

13. Erinjeri, J.P.; Fine, G.C.; Adema, G.J.; Ahmed, M.; Chapiro, J.; Brok, M.; Duran, R.; Hunt, S.J.; Johnson, T.; Ricke, J.; et al. Immunotherapy and the interventional oncologist: Challenges and opportunities-A society of interventional oncology white paper. Radiology 2019, 292, 25-34. [CrossRef] [PubMed]

14. Quinto, A.M.; Nutu, O.; Manso, R.S.R.; Alonso, I.J.; Pulido, J.; Municio, A.M.; García-Sesma, A.; Segurola, C.L.; Caballero, J.M.; Romero, L.C. Complications of transarterial chemoembolization (TACE) in the treatment of liver tumors. Cirugia Es-Panola 2018, 96, 560-567.

15. Chen, Y.P.; Zhang, J.L.; Zou, Y.; Wu, Y.L. Recent Advances on Polymeric Beads or Hydrogels as Embolization Agents for Improved Transcatheter Arterial Chemoembolization (TACE). Front. Chem. 2019, 7, 408. [CrossRef] [PubMed]

16. Li, H.; Wu, F.; Duan, M.; Zhang, G. Drug-eluting bead transarterial chemoembolization (TACE) vs conventional TACE in treating hepatocellular carcinoma patients with multiple conventional TACE treatments history: A comparison of efficacy and safety. Medicine 2019, 98, e15314. [CrossRef] [PubMed]

17. Idee, J.M.; Guiu, B. Use of Lipiodol as a drug-delivery system for transcatheter arterial chemoembolization of hepatocellular carcinoma: A review. Crit. Rev. Oncol. Hematol. 2013, 88, 530-549. [CrossRef]

18. Woo, H.Y.; Heo, J. Transarterial chemoembolization using drug eluting beads for the treatment of hepatocellular carcinoma: Now and future. Clin. Mol. Hepatol. 2015, 21, 344-348. [CrossRef]

19. Nicholson, T.A.; Pelage, T.P.; Ettles, D.F. Fibroid Calcification after Uterine Artery Embolization: Ultrasonographic Appearance and Pathology. J. Vasc. Interv. Radiol. 2001, 12, 443-446. [CrossRef]

20. Lee, M.W.; Tsai, H.F.; Wen, S.M.; Huang, C.H. Photocrosslinkable gellan gum film as an anti-adhesion barrier. Carbohydr. Polym. 2012, 90, 1132-1138. [CrossRef]

21. Tsai, W.C.; Tsai, H.F.; Wong, Y.A.; Hong, J.Y.; Chang, S.J.; Lee, M.W. Preparation and characterization of gellan gum/glucosamine / clioquinol film as oral cancer treatment patch. Mater. Sci. Eng. C 2018, 82, 317-322. [CrossRef]

22. Hsu, M.F.; Tyan, Y.S.; Chien, Y.C.; Lee, M.W. Hyaluronic acid-based nano-sized drug carrier-containing Gellan gum microspheres as potential multifunctional embolic agent. Sci. Rep. 2018, 8, 731-740. [CrossRef]

23. Osmałek, T.; Froelich, A.; Tasarek, S. Application of gellan gum in pharmacy and medicine. Int. J. Pharm. 2014, 466, 328-340. [CrossRef]

24. Silva-Correia, J.; Oliveira, J.M.; Caridade, S.G.; Oliveira, J.T.; Sousa, R.A.; Mano, J.F.; Reis, R.L. Gellan gum-based hydrogels for intervertebral disc tissue-engineering applications. J. Tissue Eng. Regen Med. 2011, 5, e97-e107. [CrossRef]

25. Kim, H.; Lee, D.; Kim, J.; Kim, T.I.; Kim, W.J. Photothermally triggered cytosolic drug delivery via endosome disruption us-ing a functionalized reduced graphene oxide. ACS Nano 2013, 7, 6735-6746. [CrossRef]

26. Zhou, J.; Han, T.; Ma, H.; Yan, T.; Pang, X.; Li, Y.; Wei, Q. A novel electro chemiluminescent immunosensor based on the quenching effect of aminated graphene on nitrogen-doped carbon quantum dots. Anal. Chim. Acta 2015, 889, 82-89. [CrossRef]

27. Björk, J.; Hanke, F.; Palma, C.A.; Samorì, P.; Cecchini, M.; Persson, M. Adsorption of aromatic and anti-aromatic systems on graphene through $\pi-\pi$ stacking. J. Phys. Chem. Lett. 2010, 1, 3407-3412. [CrossRef]

28. Karki, N.; Tiwari, H.; Tewari, C.; Rana, A.; Pandey, N.; Basak, S.; Sahoo, N.G. Functionalized graphene oxide as a vehicle for targeted drug delivery and bioimaging applications. J. Mater. Chem. B 2020, 8, 8116-8148. [CrossRef]

29. Li, Y.; Yuan, H.; von dem Bussche, A.; Creighton, M.; Hurt, R.H.; Kane, A.B.; Gao, H. Graphene microsheets enter cells through spontaneous membrane penetration at edge asperities and corner sites. Proc. Natl. Acad. Sci. USA 2013, 110, 12295-12300. [CrossRef]

30. Chen, H.J.; Zhang, Z.H.; Cai, R.; Chen, X.; Liu, Y.N.; Rao, W.; Yao, S.Z. Molecularly imprinted electrochemical sensor based on amine group modified graphene covalently linked electrode for 4-nonylphenol detection. Talanta 2013, 115, 222-227. [CrossRef]

31. Pruna, A.; Cárcel, A.; Benedito, A.; Giménez, E. Hydrothermal-Freeze-Casting of Poly(amidoamine)-Modified Graphene Aerogels towards CO2 Adsorption. Int. J. Mol. Sci. 2021, 22, 9333. [CrossRef]

32. Fang, F.; Kong, L.; Huang, J.; Wu, S.; Zhang, K.; Wang, X.; Sun, B.; Jin, Z.; Wang, J.; Huang, X.J.; et al. Removal of cobalt ions from aqueous solution by an amination graphene oxide nanocomposite. J. Hazard. Mater. 2014, 270, 1-10. [CrossRef] [PubMed]

33. Wang, C.Y.; Xia, J.G.; Yang, Z.Q.; Zhou, W.Z.; Chen, W.H.; Qi, C.J.; Gu, J.P.; Wang, Q. Transarterial chemoembolization with medium-sized doxorubicin-eluting Callisphere is safe and effective for patients with hepatocellular carcinoma. Sci. Rep. 2020, 10, 4434. [CrossRef]

34. Siddique, Y.H.; Khan, W.; Khanam, S.; Jyoti, S.; Naz, F.; Rahul Singh, B.R.; Naqvi, A.H. Toxic potential of synthesized graphene zinc oxide nanocomposite in the third instar larvae of transgenic Drosophila melanogaster (hsp70-lacZ) Bg9. Bio-Med. Res. Int. 2014, 2014, 382124. [CrossRef] 
35. Siddique, Y.H.; Fatima, A.; Jyoti, S.; Naz, F.; Rahul Khan, W.; Singh, B.R.; Naqvi, A.H. Evaluation of the toxic potential of graphene copper nanocomposite (GCNC) in the third instar larvae of transgenic Drosophila melanogaster (hsp70-lacZ) Bg9. PLoS ONE 2013, 8, e80944. [CrossRef]

36. Dash, S.; Murthy, P.N.; Nath, L.; Chowdhury, P. Kinetic modeling on drug release from controlled drug delivery systems. Acta Pol. Pharm. 2010, 67, 217-223. [PubMed]

37. Kasiński, A.; Zielińska-Pisklak, M.; Kowalczyk, S.; Plichta, A.; Zgadzaj, A.; Oledzka, E.; Sobczak, M. Synthesis and Characterization of New Biodegradable Injectable Thermosensitive Smart Hydrogels for 5-Fluorouracil Delivery. Int. J. Mol. Sci. 2021, 22, 8330. [CrossRef]

38. Nokhodchi, A.; Raja, S.; Patel, P.; Asare-Addo, K. The role of oral controlled release matrix tablets in drug delivery systems. Bioimpacts 2012, 2, 175-187. [PubMed]

39. Keremidarska-Markova, M.; Hristova-Panusheva, K.; Andreeva, T.; Speranza, G.; Wang, D.; Krasteva, N. Cytotoxicity Evaluation of Ammonia-Modified Graphene Oxide Particles in Lung Cancer Cells and Embryonic Stem Cells. Adv. Condens. Matter. Phys. 2018, 18, 9571828. [CrossRef]

40. Park, C.S.; Choi, K.S.; Shin, J.W.; Kim, S.Y. Inhibition of viability of the respiratory epithelial cells using functionalized graphene oxide. J. Nanosci. Nanotechnol. 2015, 15, 2060-2066. [CrossRef]

41. Feng, X.; Chen, L.; Guo, W.; Zhang, Y.; Lai, X.; Shao, L.; Li, Y. Graphene oxide induces p62/SQSTM-dependent apoptosis through the impairment of autophagic flux and lysosomal dysfunction in PC12 cells. Acta Biomater. 2018, 81, 278-292. [CrossRef] [PubMed]

42. Yan, H.; Tao, X.; Yang, Z.; Li, K.; Yang, H.; Li, A.; Cheng, R. Effects of the oxidation degree of graphene oxide on the adsorp-tion of methylene blue. J. Hazard. Mater. 2014, 268, 191-198. [CrossRef] [PubMed] 